\section{NEONATAL OUTCOMES OF LARGE-FOR- GESTATIONAL AGE INFANTS DELIVERED BY WOMEN WITH AND WITHOUT GESTATIONAL DIABETES MELLITUS?}

E. Onal, I.M. Hirfanoglu, S. Beken, N. Altuntas, C. Turkyilmaz, O. Turan, E. Ergenekon, E. Koc, Y. Atalay

Department of Pediatrics, Gazi University Medical School, Ankara, Turkey

Objective: The objective of the study was to compare the neonatal outcomes of large-for-gestational age (LGA) infants delivered by women with and without gestational diabetes mellitus (GDM).

Methods: This was a retrospective study of LGA singleton infants of $\geq 36$ weeks of gestation born at the Gazi University Medical School Hospital between 2006-2009. Neonatal outcomes included hypoglycemia, polycythemia in early neonatal period and hospital admissions. The Chi-square and Student's t-test were used for comparing variables.

Results: Seven hundred eligible infant- mother pairs were included into the study. 87 of them (12.4\%) were infants of diabetic mothers (IDMs) and 613 ( $87.6 \%)$ were infants of non-IDMs. Incidence of hypoglycemia at the first hour were higher in diabetic group (12.8\%) compared to non-IDMs (5.3\%) $(p=0.014)$. Polycythemia were also more frequently observed in IDMs $(9.3 \%)$ than non-IDMs (3.0 \%) $(p=0.010)$. Although overall hospital admission rates weren't different between groups, IDMs were more likely to be admitted due to resistant hypoglycemia $(p=0.045)$.

Conclusions: The results of this study suggested that LGA infants of women with GDM were at risk for hypoglycemia and polycythemia in early neonatal period. However, routine care was sufficient for healthy LGA infants from non-diabetic mothers.

1234

\section{LANGUAGE ASSESSMENT OF NON- HANDICAPPED TWINS}

K. Gucuyener ${ }^{1}$, E. Arhan ${ }^{1}$, S. Soysal ${ }^{1}$, E. Ergenekon², C. Turkyılmaz², E. Koc², O. Esra², O. Turan ${ }^{2}$, Y. Atalay ${ }^{2}$

${ }^{1}$ Pediatric Neurology, ${ }^{2}$ Neonatology, Gazi University Medical Faculty, Ankara, Turkey

Background aims: At present, we know very little about whether such language delay should be seen in healthy non-handicapped children. The present study was designed to evaluate language development of twin children in comparison with singletons after excluding children with overt handicap.

Methods: We performed a prospective study of a large cohort of all children born between 1 January 2001 and 31 December 2003 at Gazi University Hospital. From this sample, we identified all liveborn twin pairs of which both twins survived, and also chose a comparable sample of families with singletons.Perinatal data were derived from medical charts. The Stanford-Binet Intelligence Scale Form, the Peabody Picture Vocabulary Test- Revised were completed at 60 months.

Results: The findings showed that twins performed worse than singletons in language development. Twin girls had better scores than twin boys. There was a statistically significant difference between the scores of term and preterm twins. No significant difference has been noted when compared according to birth order. AGA twins did better than SGA twins in the test scores. Twin girls did not differ from singleton girls, but twin boys performed worse than singleton boys, all preterm twins had lower scores than preterm singletons. SGA singletons had better scores than SGA twins, AGA twins and singletons did not differ.

Conclusion: It is hoped that the findings of comparison of language development of nonhandicapped twins with singletons could lead a more precise assessment of language development in twins and if needed more efficient preventive internventions in this group.

\section{5}

FOLLOW-UP FOR NEUROLOGIC DISABILITIES IN VERY LOW WEIGHT NEWBORN CHILDREN ATTENDED IN THIRD CARE LEVEL UNIT

\author{
E.C. Urbina ${ }^{1}$, M.F. Castro ${ }^{2}$, J.C.S. Herrera ${ }^{3}$
}

${ }^{1}$ Neonatology Care Unit, ${ }^{2}$ Pediatrics Unit, ${ }^{3}$ Pediatric Oncology Unit, Mexican Social Security Institute, Cd. Obregón, Mexico

Aim: Determine most common neurological disabilities in very low weigth newborns attended in third care level unit.

Methods: A cohort design study was formed during a third year period, with very low weight newborn children's in alertness for neurological development 